\title{
Imagen del Perú y los peruanos en un grupo de universitarios chilenos
}

\author{
Alfredo Zambrano Mora \\ Universidad de Lausana \\ Lausana, Suiza \\ Ramón León \\ Luis Escurra \\ Universidad de Lima
}

\begin{abstract}
Recibido: 20 de mayo del 2017 / Aceptado: 8 de junio del 2017 doi: https://doi.org/10.26439/persona2017.n20.1742
\end{abstract}

En este estudio, se comparó la percepción de la sociedad peruana y chilena que presentaba una muestra de 453 universitarios chilenos (247 hombres y 206 mujeres, entre 16 y 48 años). Para ello, se aplicaron dos escalas: la primera, que evaluó a la sociedad peruana y chilena; y la segunda, conformada por tres subescalas - "tú", "un(a) chileno(a) como tú", "un(a) peruano(a) como tú"-, en la que se les pedía que evaluaran 20 rasgos característicos (ambicioso, responsable, tenaz, inteligente, etcétera). Los resultados indicaron que la sociedad chilena fue vista como más moderna, democrática, cercana al primer mundo, en comparación con la peruana, pero los niveles de corrupción y de pobreza fueron percibidos como muy semejantes en los dos países. En tanto que el chileno fue valorado como competitivo, el peruano recibió un puntaje superior como emprendedor.

imagen del Perú / estudiantes chilenos / comparación de sociedades

\section{Perception of Peru and Peruvian Citizens in a Sample of Chilean College Students}

We examined and compared perceptions Chilean college students have of the Peruvian and their own society. To this end, we studied a sample of 453 students (247 males, and 206 females, ages between 16 and 48). Two scales were used, one evaluated Peruvian and Chilean societies and the second scale was subdivided into three components (You, A Chilean like you, A Peruvian like you) to evaluate common traits (ambitious, responsible, tenacious, and intelligent). Results indicate that the perception of the sample revealed that Chilean society was more modern, democratic, and close to First World standards than the Peruvian. Levels of poverty and corruption were perceived as similar. Finally, Chileans were considered more competitive, whereas Peruvian more entrepreneurial.

Chilean perception of Peruvians / Chilean college students / society comparison

Correo electrónico: lescurra@ulima.edu.pe 
Chile es un país que, a lo largo de su historia, ha tenido relaciones difíciles con sus tres vecinos: Argentina, Bolivia y Perú (Artaza Rouxel y Milet García, 2007; González Madariaga, 1970), pero especialmente con los dos últimos, con los que protagonizó una sangrienta confrontación militar en el último cuarto del siglo XIX, conocida como la Guerra del Pacífico, sobre la cual existe una amplia literatura (por ejemplo, Cavieres Figueroa, 2006; León, 2004, 2006; Sater, 2007; Cluny, 2008; Hosiasson, 2011; Sirlopú y León, 2016).

$\mathrm{Si}$ bien esa guerra ocurrió hace cerca de ciento cincuenta años, sus consecuencias se siguen sintiendo hasta hoy: aunque en 1929 se firmó el Tratado de Ancón mediante el cual Perú y Chile sellaron la paz, los problemas de precisión en materia de delimitación marítima se han solucionado tan solo hace muy poco, después que ambas naciones sometieran sus diferencias ante la Corte Internacional de Justicia de La Haya (Ministerio de Relaciones Exteriores del Perú, s. f.; Ahumada y Rivas Pardo, 2010; Leiva Lavalle, 2010).

Con Bolivia las relaciones han sido aún más complicadas y continúan siéndolo, tanto que desde 1978 no existen relaciones diplomáticas entre los dos países. En 1904, un tratado de paz puso fin, teóricamente, a la enemistad existente entre ellos, pero a lo largo del siglo xx Bolivia ha elevado quejas debido a la pérdida de territorio que se vio obligada a aceptar con ese tratado, y a la forzada mediterraneidad surgida con él. En la actualidad, ha presentado un reclamo ante la Corte Internacional de Justicia de La Haya para que se inicien conversaciones destinadas a devolverle la condición de país marítimo. Para los bolivianos, el no tener acceso al mar es considerado como una de las causas de la pobreza del país (Brockmann, 2014), y para Chile, el problema con Bolivia "genera una tensión permanente que, a pesar de algunos intentos por ignorarla, termina apareciendo una y otra vez en la superficie" (Lacoste y Jiménez Cabrera, 2016, p. 121).

Pese a estos problemas, el intercambio comercial y de personas entre las tres naciones es cada vez más intenso. En particular, las inversiones chilenas en el Perú son muy elevadas, y las del Perú en Chile van en aumento. Tanto Chile como Perú forman parte de la así llamada Alianza del Pacífico. Concluida la causa llevada ante la Corte Internacional de Justicia de La Haya, ambos gobiernos han reiterado su deseo de una convivencia pacífica y de una mayor actividad comercial para beneficio de sus respectivas economías.

Todo esto se encuentra en la base del interés que la opinión pública de cada uno de los países tiene por lo que ocurre en el otro. Comparaciones en materia de economía, de vida política y, por supuesto, de poderío militar son frecuentemente presentadas en los medios de comunicación o por políticos (véase: Milet, 2004; Aranda Bustamante, 2010; "Éxito peruano...", 2013). Así, por ejemplo, el presidente peruano Alan García, al iniciar su segundo periodo presidencial en 2010, señaló en su mensaje a la Nación que su meta era que el 
Perú alcanzara a Chile en algunos de los más importantes indicadores de desarrollo social y económico.

El interés por lo que le sucede al vecino se ve alimentado, asimismo, por el hecho de que desde la década de 1980 se ha producido un intensivo proceso de migración de peruanos a Chile, impulsados por la búsqueda de un futuro mejor y huyendo de los graves problemas económicos que afectaban al Perú en ese tiempo (Araujo, Legua y Ossandón, 2002); los migrantes estaban atraídos por el progreso del vecino del sur, que coincidía con el retorno de la democracia, tras el fin del régimen de Augusto Pinochet (Mora, 2008).

Ciertamente, no solo a Chile han emigrado peruanos (Altamirano, 1992, 1996; Paerregaard 2008), ni los peruanos son los únicos que se han establecido en ese país. El censo del año 2002 señalaba que las comunidades de inmigrantes más numerosas provenían de Argentina, Perú, Bolivia y Ecuador, respectivamente (Muñoz, 2005), algo que ha sido calificado como la nueva inmigración, pero esta vez andina, en comparación con la que ocurrió hacia mediados de los años 1980, que era predominantemente europea. La comunidad peruana está concentrada sobre todo en Santiago, lo que le da una mayor visibilidad social (Muñoz, 2005).

De hecho, como lo señalan Núñez y Stefoni (2004), siempre ha habido migración peruana a Chile, pero "lo novedoso es que, en estos últimos años, este flujo de personas dejó de estar circunscrito a la zona Tacna-Arica para transformarse en una migración de carácter más bien económico, con personas provenientes de la costa norte del Perú y que llegan a la zona centro de Chile" (p. 105). También lo es la presencia cada vez mayor de capitales chilenos en el Perú: las inversiones chilenas en el Perú alcanzaron los 9550 millones de dólares en el stock acumulado al 2012, lo que representa el 9,8\% del total invertido por Chile en el mundo (Ministerio de Relaciones Exteriores de Chile, 2013).

El número de peruanos que actualmente viven en Chile ronda los cien mil, legalmente inscritos. La cercanía geográfica, la ausencia de problemas en la comunicación dado el mismo lenguaje, y el progreso económico experimentado por Chile en los últimos treinta años han hecho de este país uno de los lugares en los que pensaban los peruanos cuando tenían el deseo o la imperiosa necesidad de emigrar. Los peruanos que se han establecido en Chile, por lo general, desempeñan actividades en el plano artesanal o en el rubro de servicios y de actividades de construcción. La recepción que han tenido ha sido variada: hay testimonios de experiencias positivas, pero también de casos en los que las cosas han estado caracterizadas por la tensión y la frustración (Correa, 2011; Lahoz i Ubacha y Forns i Santacana, 2016).

La presencia de peruanos en Chile, que, como ya se dijo, recibió en el pasado predominantemente emigración europea (con notoria influencia en la cultura de ese país; Doña-Reveco y Levinson, 2012), ha sido objeto de numerosos estudios (por ejemplo, Araujo et al., 2002; Stefoni, 2002, 2003; Navarrete Yáñez, 2007; Riquelme 
y Alarcón, 2008; Torres e Hidalgo, 2009; González, Sirlopú y Kessler, 2010; Hernández Sánchez, 2011; Vásquez, 2014). Y también ha sido tomada en cuenta tanto en el Perú como en Chile en los momentos de tensión que se han vivido en los últimos años, especialmente en la contienda jurídica que dio lugar a la presentación de un caso ante la Corte Internacional de Justicia de La Haya (Hernández Sánchez, 2011).

Los procesos migratorios traen como consecuencia positiva el conocimiento de otras culturas por parte de los que emigran, así como por parte de los que reciben a los inmigrantes. Una consecuencia negativa frecuente es, sin embargo, el desarrollo de prejuicios negativos o de actitudes xenofóbicas, además del temor de que la identidad nacional, o lo que se entienda por ella, pueda verse afectada. En el contacto entre inmigrantes y locales se va, de otro lado, forjando la imagen del otro, en este caso, de los peruanos en Chile.

Poco se ha explorado cuál es la imagen que los peruanos tienen de los chilenos, y viceversa. Se cuenta con testimonios y ensayos, así como con visiones de naturaleza impresionista, que son comentadas entre el gran público (Tory, 2013). En el marco del presente trabajo, se investiga cómo percibe un grupo de estudiantes universitarios chilenos a los chilenos mismos y a los peruanos.

\section{MATERIAL Y MÉTODO}

Se analizó, en total, a 453 estudiantes universitarios (247 hombres y 206 mujeres, entre 16 y 48 años de edad), residentes en Santiago de Chile. Respondieron de modo anónimo y colectivo dos escalas construidas por los autores, en las cuales se les pedía su valoración con referencia a una serie de cuestiones integradas en ellas.

La primera escala, denominada "Imagen de la sociedad", comprendía 31 ítems referidos a una serie de aspectos de la vida social de Chile y Perú, por ejemplo, el nivel de democracia, el nivel de pobreza, la seguridad ciudadana en cada país, el nivel de racismo, etcétera. Se solicitó a los integrantes de la muestra que valoraran cada uno de ellos en una escala de 1 a 5 . La segunda escala, llamada "Imagen personal", incluía un total de 20 adjetivos, tales como ambicioso, agresivo, inteligente, que debían ser evaluados igualmente en una escala de 1 a 5 en tres rubros: "tú", "un(a) chileno(a) como tú" y "un(a) peruano(a) como tú".

Tres preguntas aparte indagaron acerca del grado de simpatía que los encuestados tenían por Argentina, Bolivia y Perú; el grado de simpatía que creían que chilenos como ellos tenían por esos tres países $\mathrm{y}$, por último, el grado de simpatía que ellos creían que argentinos, bolivianos y peruanos como ellos sentían por Chile.

\section{Resultados}

\section{Propiedades psicométricas de los instrumentos empleados}

En la escala "Imagen de la sociedad", para Chile la correlación ítem-total de la mayoría de los ítems fue mayor a .25 , excepto en los siguientes casos: ítem 8 (nivel de pobreza del país: .009), ítem 14 (agresividad militar del país: .169), ítem 
15 (corrupción en el país: -.101), ítem 21 (nivel de racismo en el país: .179), ítem 28 (nivel de antiamericanismo en el país: .152 ), ítem 30 (influencia de la Iglesia católica: .222) e ítem 31 (deseos de irse del país por parte de los jóvenes: .003). Dado que el retiro de estos ítems no modificaba de modo sustantivo el nivel de confiabilidad de la escala, se decidió conservarlos. El nivel de confiabilidad fue bastante elevado: alfa $=.859$. En el caso del Perú, la mayoría de ítems tuvo una correlación con el total por encima de .25 , excepto los ítems 8 (nivel de pobreza del país: .207), 15 (corrupción en el país: .069), 21 (nivel de racismo en el país: .169), 28 (nivel de antiamericanismo en el país: .226) y 31 (deseos de irse del país por parte de los jóvenes: .055). El alfa fue de .851 .

Con respecto a la escala "Imagen personal", los ítems de la escala correspondiente a "tú" presentaron en su gran mayoría una correlación con el puntaje total superior a .25 , excepto el ítem 1 (ambicioso: .156), 11 (agresivo: .001) y 15 (ahorrativo: .143). El alfa de toda la escala fue de .818. En la escala "un chileno como tú", solo dos ítems arrojaron una correlación con el total por debajo de .25: el 11 (agresivo: .158) y el 20 (inteligente: .233). El alfa obtuvo un valor de .865. Finalmente, en la escala "un peruano como tú", solo un ítem estuvo por debajo de .25: el 11 (agresivo: $.149)$. El alfa fue .882 .

\section{Aspectos de las sociedades chilena y peruana}

La tabla 1 presenta los promedios obtenidos por ambos países en la escala "Imagen de la sociedad". En la mayoría de los ítems, los integrantes de la muestra valoraron más favorablemente a su país que al Perú, excepto en la confianza entre las personas en el país, en el respeto a minorías sexuales y en los deseos de irse del país por parte de los jóvenes.

En otros ítems, hubo una suerte de empate técnico (ítem 6, patriotismo de los ciudadanos; ítem 8 , nivel de pobreza del país; ítem 14, agresividad militar del país; ítem 15, corrupción en el país; ítem 17, confianza en el poder judicial en el país).

En el caso de Chile, los cinco aspectos con los promedios más elevados fueron atractivo turístico del país, atractivo para los inversionistas extranjeros, patriotismo de los ciudadanos, importancia del país en el contexto latinoamericano y agresividad militar del país.

En el caso del Perú, fueron atractivo turístico del país, patriotismo de los ciudadanos, corrupción en el país, identificación de los ciudadanos con su país y nivel de pobreza del país. Seguidamente, se procedió a realizar un análisis factorial exploratorio de los resultados de Chile (véase la tabla 2). 
Tabla 1

Promedios obtenidos por Chile y Perú en la escala "Imagen de la sociedad"

\begin{tabular}{|c|c|c|c|c|c|}
\hline $\mathrm{N} .^{\circ}$ & Aspecto & Chile & Perú & $Z$ & $r$ \\
\hline 1. & Nivel de democracia del país & 3,10 & 2,86 & $-4,91 * * *$ & .23 \\
\hline 2. & Desarrollo económico del país & 3,47 & 2,53 & $-13,72^{* * *}$ & .64 \\
\hline 3. & Igualdad de oportunidades para todos los ciudadanos & 2,73 & 2,45 & $-4,61^{* * *}$ & .22 \\
\hline 4. & Poderío militar del país & 3,46 & 2,92 & $-8,04 * * *$ & .38 \\
\hline 5. & Posibilidad de progreso personal en el país & 3,39 & 2,66 & $-10,12$ & .48 \\
\hline 6. & Patriotismo de los ciudadanos & 3,77 & 3,74 & $-0,47$ & .02 \\
\hline 7. & Nivel de calidad de vida del país & 3,33 & 2,53 & $-11,95^{* * *}$ & .56 \\
\hline 8. & Nivel de pobreza del país & 3,21 & 3,25 & $-0,43$ & .02 \\
\hline 9. & Seguridad ciudadana en el país & 2,91 & 2,66 & $-4,44^{* * *}$ & .21 \\
\hline 10. & Importancia del país en el contexto latinoamericano & 3,67 & 2,79 & $-12,49^{* * *}$ & .59 \\
\hline 11. & Importancia del país en el contexto mundial & 3,06 & 2,49 & $-7,68^{* * *}$ & .36 \\
\hline 12. & Atractivo turístico del país & 4,14 & 3,94 & $-3,55^{* * *}$ & .17 \\
\hline 13. & Atractivo para inversionistas extranjeros & 3,88 & 3,09 & $-11,39 * * *$ & .54 \\
\hline 14. & Agresividad militar del país & 3,05 & 3,09 & $-0,65$ & .03 \\
\hline 15. & Corrupción en el país & 3,66 & 3,63 & $-0,51$ & .02 \\
\hline 16. & Respeto por los derechos humanos en el país & 3,14 & 2,88 & $-5,20^{* * *}$ & .24 \\
\hline 17. & Confianza en el poder judicial del país & 2,50 & 2,45 & $-0,56$ & .03 \\
\hline 18. & Confianza en los políticos del país & 2,03 & 2,36 & $-5,99 * * *$ & .28 \\
\hline 19. & Confianza entre las personas en el país & 2,75 & 2,77 & $-0,23$ & .01 \\
\hline 20. & Respeto a minorías sexuales en el país & 2,48 & 2,58 & $-1,97^{*}$ & .09 \\
\hline 21. & Nivel de racismo en el país & 3,52 & 3,02 & $-8,32^{* * *}$ & .39 \\
\hline 22. & Igualdad de derechos entre hombres y mujeres en el país & 3,10 & 2,75 & $-7,07^{* * *}$ & .33 \\
\hline 23. & Eficiencia del Estado en el país & 2,84 & 2,64 & $-4,35^{* * *}$ & .20 \\
\hline 24. & Nivel cultural de la población & 3,02 & 2,91 & $-2,10^{*}$ & .10 \\
\hline 25. & $\begin{array}{l}\text { Posibilidad de llegar a ser pronto un país del primer } \\
\text { mundo }\end{array}$ & 2,80 & 2,17 & $-9,10^{* * *}$ & .43 \\
\hline 26. & Identificación de los ciudadanos con su respectivo país & 3,51 & 3,39 & $-1,96^{*}$ & .09 \\
\hline 27. & Nivel de antihispanismo en el país & 2,88 & 2,74 & $-3,04^{* *}$ & .14 \\
\hline 28. & Nivel de antiamericanismo en el país & 2,74 & 2,66 & $-1,43$ & .07 \\
\hline 29. & Nivel de satisfacción de los ciudadanos con su sociedad & 2,85 & 2,69 & $-3,12^{* *}$ & .15 \\
\hline 30. & Influencia de la Iglesia católica en el país & 3,56 & 3,23 & $-6,03^{* * *}$ & .28 \\
\hline 31. & Deseos de irse del país por parte de los jóvenes & 3,59 & 3,91 & $-4,80 * * *$ & .23 \\
\hline
\end{tabular}

Nota: ${ }^{*} p<.05,{ }^{* *} p<.01,{ }^{* *} p<.001$. Se aplicó la prueba de Wilcoxon de los rangos y $r$ como medida del tamaño del efecto. 
Tabla 2

Análisis factorial exploratorio de Chile en la escala "Imagen de la sociedad"

\begin{tabular}{|c|c|c|c|c|c|}
\hline N. ${ }^{\circ}$ & Aspecto & I & II & III & IV \\
\hline 1. & Nivel de democracia del país & .533 & & & \\
\hline 2. & Desarrollo económico del país & & .647 & & \\
\hline 3. & Igualdad de oportunidades para todos los ciudadanos & .527 & & & \\
\hline 4. & Poderío militar del país & & .442 & & \\
\hline 5. & Posibilidad de progreso personal en el país & & .573 & & \\
\hline 6. & Patriotismo de los ciudadanos & & & & .669 \\
\hline 7. & Nivel de calidad de vida del país & & .651 & & \\
\hline 8. & Nivel de pobreza del país & & & .494 & \\
\hline 9. & Seguridad ciudadana en el país & & .487 & & \\
\hline 10. & Importancia del país en el contexto latinoamericano & & .773 & & \\
\hline 11. & Importancia del país en el contexto mundial & & .592 & & \\
\hline 12. & Atractivo turístico del país & & & & .448 \\
\hline 13. & Atractivo para inversionistas extranjeros & & 669 & & \\
\hline 14. & Agresividad militar del país & & & .445 & \\
\hline 15. & Corrupción en el país & & & .536 & \\
\hline 16. & Respeto por los derechos humanos en el país & .585 & & & \\
\hline 17. & Confianza en el poder judicial del país & .705 & & & \\
\hline 18. & Confianza en los políticos del país & .716 & & & \\
\hline 19. & Confianza entre las personas en el país & .590 & & & \\
\hline 20. & Respeto a minorías sexuales en el país & 610 & & & \\
\hline 21. & Nivel de racismo en el país & & .401 & & \\
\hline 22. & Igualdad de derechos entre hombres y mujeres en el país & .401 & & & \\
\hline 23. & Eficiencia del Estado en el país & 654 & & & \\
\hline 24. & Nivel cultural de la población & 602 & & & \\
\hline 25. & $\begin{array}{l}\text { Posibilidad de llegar a ser pronto un país del primer } \\
\text { mundo }\end{array}$ & & .433 & & \\
\hline 26. & Identificación de los ciudadanos con su respectivo país & & & & .690 \\
\hline 27. & Nivel de antihispanismo en el país & & & .446 & \\
\hline 28. & Nivel de antiamericanismo en el país & & & .536 & \\
\hline 29. & Nivel de satisfacción de los ciudadanos con su sociedad & 657 & & & \\
\hline 30. & Influencia de la Iglesia católica en el país & & .348 & & \\
\hline 31. & Deseos de irse del país por parte de los jóvenes & & & .607 & \\
\hline & Autovalores & 7.57 & 2.61 & 1.89 & 1.42 \\
\hline & $\%$ de varianza explicada & 17.21 & 13.61 & 6.47 & 6.20 \\
\hline
\end{tabular}


Asimismo, se llevó a cabo un análisis factorial exploratorio de los resultados obtenidos en la escala "Imagen de la sociedad", en lo referente a Chile. La tabla 2 muestra los resultados del análisis, donde se observaron cuatro factores que explicaron el 43,49 \% de la varianza. El factor I, calidad de vida, agrupó 11 ítems referidos a aspectos tales como el nivel de democracia del país, la confianza en los políticos, el respeto a minorías sexuales. El promedio fue 2,77. El factor II, desarrollo, comprendió también 11 ítems, esta vez acerca del desarrollo económico del país, su poderío militar, la posibilidad del progreso personal, así como la importancia del país en el contexto mundial. El promedio fue 3,36. Por su parte, el factor III, imagen negativa del país, estaba conformado por 6 ítems que evaluaban la pobreza del país, su agresividad militar, la corrupción y los niveles de antihispanismo y antiamericanismo. El promedio fue 3,18. Por último, el factor IV, amor por el país, lo integraron tres ítems sobre la belleza del país, la identificación con él y el patriotismo de los chilenos. El promedio fue 3,80.

En el análisis factorial exploratorio de la escala "Imagen de la sociedad", referida al Perú, se obtuvieron, asimismo, cuatro factores que explicaron el 40,22\% de la varianza. El factor I, democracia, abarcó 13 ítems referidos al nivel de democracia, desarrollo económico y las posibilidades de progreso personal. El promedio fue 2,62. El factor II, identificación con el país, estuvo conformado por 9 ítems sobre el patriotismo de los peruanos, el atractivo turístico del país y la identificación con el Perú. El promedio fue 3,47. El factor III, calidad de vida, con 6 ítems, integraba aspectos tales como la confianza interpersonal, la confianza en los políticos $\mathrm{y}$ el respeto por los derechos humanos. El promedio fue 2,66. Por último, el factor IV, racismo y xenofobia, estaba conformado por 3 ítems referidos al racismo, el antihispanismo y el antiamericanismo en el país. El promedio fue 2,80.

\section{Escala de imagen personal}

En lo concerniente a los resultados de la escala de imagen personal, en la tabla 4 , se puede apreciar que en la mayoría de los ítems los sujetos de la muestra valoraron mejor a sus compatriotas que a los peruanos, excepto en los ítems honesto, responsable, ahorrativo, en los que los peruanos obtuvieron promedios más altos que los chilenos. Puede observarse, además, que el puntaje más alto entre los sujetos de la muestra al momento de evaluarse ellos mismos fue el de confiable, seguido por honesto, divertido, sociable e inteligente. $\mathrm{Al}$ momento de valorar a sus compatriotas, el promedio más alto lo obtuvo competitivo, seguido por divertido, sociable, solidario y ambicioso. En lo que se refiere a la valoración de los peruanos, el promedio más alto corresponde a emprendedor, seguido por sociable, responsable, ambicioso y orgulloso. 
Tabla 3

Análisis factorial exploratorio de Perú en la escala "Imagen de la sociedad"

\begin{tabular}{|c|c|c|c|c|c|}
\hline N..$^{\circ}$ & Aspecto & 1 & II & III & IV \\
\hline 1. & Nivel de democracia del país & .515 & & & \\
\hline 2. & Desarrollo económico del país & .471 & & & \\
\hline 3. & Igualdad de oportunidades para todos los ciudadanos & .711 & & & \\
\hline 4. & Poderío militar del país & .496 & & & \\
\hline 5. & Posibilidad de progreso personal en el país & 659 & & & \\
\hline 6. & Patriotismo de los ciudadanos & & .561 & & \\
\hline 7. & Nivel de calidad de vida del país & .558 & & & \\
\hline 8. & Nivel de pobreza del país & & .430 & & \\
\hline 9. & Seguridad ciudadana en el país & 643 & & & \\
\hline 10. & Importancia del país en el contexto latinoamericano & .472 & & & \\
\hline 11. & Importancia del país en el contexto mundial & .752 & & & \\
\hline 12. & Atractivo turístico del país & & .668 & & \\
\hline 13. & Atractivo para inversionistas extranjeros & & .446 & & \\
\hline 14. & Agresividad militar del país & & .483 & & \\
\hline 15. & Corrupción en el país & & .542 & & \\
\hline 16. & Respeto por los derechos humanos en el país & & & .590 & \\
\hline 17. & Confianza en el poder judicial del país & & & .736 & \\
\hline 18. & Confianza en los políticos del país & & & .545 & \\
\hline 19. & Confianza entre las personas en el país & & & .492 & \\
\hline 20. & Respeto a minorías sexuales en el país & .517 & & & \\
\hline 21. & Nivel de racismo en el país & & & & .540 \\
\hline 22. & Igualdad de derechos entre hombres y mujeres en el país & .390 & & & \\
\hline 23. & Eficiencia del Estado en el país & & & .542 & \\
\hline 24. & Nivel cultural de la población & & & .469 & \\
\hline 25. & $\begin{array}{l}\text { Posibilidad de llegar a ser pronto un país del primer } \\
\text { mundo }\end{array}$ & .671 & & & \\
\hline 26. & Identificación de los ciudadanos con su respectivo país & & .540 & & \\
\hline 27. & Nivel de antihispanismo en el país & & & & .712 \\
\hline 28. & Nivel de antiamericanismo en el país & & & & .587 \\
\hline 29. & Nivel de satisfacción de los ciudadanos con su sociedad & .458 & & & \\
\hline 30. & Influencia de la Iglesia católica en el país & & .497 & & \\
\hline 31. & Deseos de irse del país por parte de los jóvenes & & .376 & & \\
\hline & Autovalores & .6581 & 2.856 & 1.632 & 1.405 \\
\hline & $\%$ de varianza explicada & 16.18 & 9.67 & 9.17 & 5.20 \\
\hline
\end{tabular}


Tabla 4

Promedios de "un(a) chileno(a) como tú" y "Un(a) peruano(a) como tú" en la escala "Imagen personal"

\begin{tabular}{|c|c|c|c|c|c|c|c|c|c|c|}
\hline \multirow[t]{2}{*}{ N. ${ }^{\circ}$} & \multirow[t]{2}{*}{ Rasgo } & \multirow[t]{2}{*}{ Tú } & \multirow{2}{*}{$\begin{array}{l}\text { Un(a) } \\
\text { chileno(a) } \\
\text { como tú }\end{array}$} & \multirow{2}{*}{$\begin{array}{l}\text { Un(a) } \\
\text { peruano(a) } \\
\text { como tú }\end{array}$} & \multicolumn{3}{|c|}{ Comparación tú-Perú } & \multicolumn{3}{|c|}{$\begin{array}{l}\text { Comparación Chile- } \\
\text { Perú }\end{array}$} \\
\hline & & & & & $Z$ & Sig. & $r$ & Z & Sig. & $r$ \\
\hline 1. & Ambicioso(a) & 3,25 & 3,64 & 3,38 & $-1,66$ & .097 & .08 & $-4,93$ & $<.001$ & .23 \\
\hline 2. & Emprendedor(a) & 3,91 & 3,51 & 3,51 & $-6,51$ & $<.001$ & .31 & $-0,03$ & .974 & .01 \\
\hline 3. & Sociable & 4,01 & 3,68 & 3,41 & $-8,47$ & $<.001$ & .40 & $-4,38$ & $<.001$ & .21 \\
\hline 4. & Competitivo(a) & 3,80 & 3,85 & 3,32 & $-7,03$ & $<.001$ & .33 & $-8,73$ & $<.001$ & .41 \\
\hline 5. & Democrático(a) & 3,85 & 3,34 & 3,22 & $-9,00$ & $<.001$ & .42 & $-2,30$ & .021 & .11 \\
\hline 6. & Ordenado(a) & 3,42 & 2,94 & 3,13 & $-3,86$ & $<.001$ & .18 & $-3,38$ & .001 & .16 \\
\hline 7. & Honesto(a) & 4,12 & 3,09 & 3,21 & $-11,53$ & $<.001$ & .54 & $-2,36$ & .018 & .11 \\
\hline 8. & Responsable & 3,83 & 3,15 & 3,40 & $-6,30$ & $<.001$ & .30 & $-4,56$ & $<.001$ & .21 \\
\hline 9. & Creativo(a) & 3,85 & 3,55 & 3,19 & $-9,01$ & $<.001$ & .42 & $-6,50$ & $<.001$ & .31 \\
\hline 10. & Seguro(a) & 3,77 & 3,37 & 3,07 & $-9,82$ & $<.001$ & .46 & $-5,56$ & $<.001$ & .26 \\
\hline 11. & Agresivo(a) & 2,46 & 3,41 & 3,25 & $-9,75$ & $<.001$ & .46 & $-2,58$ & .010 & .12 \\
\hline 12. & Previsor(a) & 3,34 & 3,04 & 3,03 & $-4,56$ & $<.001$ & .21 & $-0,15$ & .883 & .01 \\
\hline 13. & Confiable & 4,20 & 3,19 & 3,04 & $-13,02$ & $<.001$ & .61 & $-2,342$ & .019 & .11 \\
\hline 14. & Orgulloso(a) & 3,60 & 3,74 & 3,36 & $-3,31$ & $<.001$ & .16 & $-6,16$ & $<.001$ & .29 \\
\hline 15. & Ahorrativo(a) & 3,21 & 2,85 & 3,21 & $-0,27$ & .782 & .01 & $-5,69$ & $<.001$ & .27 \\
\hline 16. & Solidario(a) & 4,01 & 3,66 & 3,26 & $-10,51$ & $<.001$ & .49 & $-6,56$ & $<.001$ & .31 \\
\hline 17. & Tenaz & 3,63 & 3,28 & 3,11 & $-8,294$ & $<.001$ & .39 & $-3,11$ & .002 & .15 \\
\hline 18. & Divertido(a) & 4,03 & 3,79 & 3,15 & $-11,08$ & $<.001$ & .52 & $-9,20$ & $<.001$ & .43 \\
\hline 19. & Atractivo(a) & 3,74 & 3,43 & 2,51 & $-13,11$ & $<.001$ & .62 & $-11,81$ & $<.001$ & .55 \\
\hline \multirow[t]{2}{*}{20.} & Inteligente & 4,00 & 3,59 & 3,34 & $-9,35$ & $<.001$ & .44 & $-4,40$ & $<.001$ & .21 \\
\hline & $\begin{array}{l}\text { Alfa de } \\
\text { Cronbach }\end{array}$ & .808 & .865 & .882 & & & & & & \\
\hline
\end{tabular}

Nota: Se aplicó la prueba de Wilcoxon de los rangos y $r$ como medida del tamaño del efecto.

\section{Niveles de simpatía}

La figura 1 presenta los niveles de simpatía en los tres aspectos en que fueron evaluados: la simpatía que los sujetos de la muestra experimentaban por argenti- nos, bolivianos y peruanos; la simpatía que ellos creían que compatriotas como ellos sentían por argentinos, bolivianos y peruanos; $y$, finalmente, la simpatía que ellos creían que argentinos, bolivianos y peruanos sentían por Chile. 


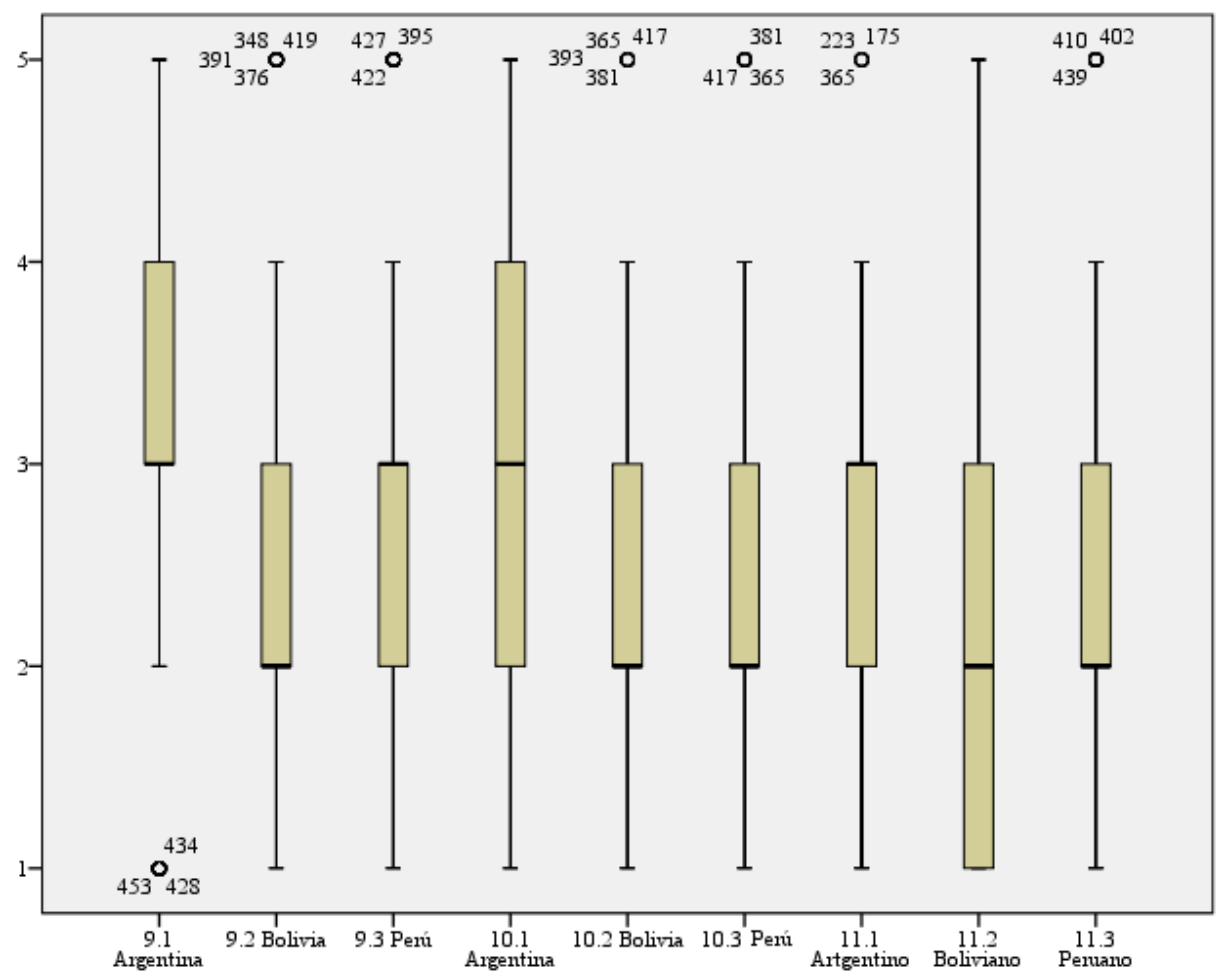

Figura 1. Diagrama de cajas de las variables estudiadas

En lo que se refiere a la simpatía que los sujetos de la muestra experimentaron por cada uno de los tres países, el promedio mayor correspondió a Argentina (M: 3,05; $D S$ : 0,993), seguida por Perú (M: 2,66; $D S: 1,063)$ y al final Bolivia $(M: 2,47 ; D S$ : 1,001). El promedio de la valoración de la simpatía de los chilenos en general hacia los tres países siguió el mismo orden que en el caso anterior: Argentina ( $M: 2,95$; $D S: 1,023)$, Perú $(M: 2,36 ; D S: 1,006)$ y Bolivia ( $M: 2,25 ; D S: 0,912)$. Finalmente, la valoración de la simpatía atribuida a los argentinos, bolivianos y peruanos hacia Chile presentó los siguientes resultados: Argentina (M: 2,70; DS: 0,905), Perú
(M: 2,$36 ; D S: 1,025)$ y Bolivia $(M: 2,16$; DS: 0,932).

\section{Análisis correlacional}

La edad presentó correlaciones estadísticamente significativas con la simpatía de los sujetos de la muestra hacia Bolivia (.095; $p<.044)$ y hacia Perú $(.168 ; p<$ $.000)$, y por la simpatía que los sujetos de la muestra creyeron que sentían los peruanos por los chilenos $(.113 ; p<.0001)$. En la tabla 5 se observan las correlaciones entre los sentimientos de simpatía de los sujetos de la muestra hacia argentinos, bolivianos y peruanos. 
Tabla 5

Correlaciones de los niveles de simpatía entre Bolivia, Chile y Perú

\begin{tabular}{lll}
\hline & Bolivia & Perú \\
\hline Simpatía de la muestra hacia... & $.317^{* *}$ & $.213^{* *}$ \\
Argentina & & $.603^{* *}$ \\
Bolivia & & \\
Simpatía de los chilenos hacia... & $.356^{* *}$ & $.238^{* *}$ \\
Argentina & & $.667^{* *}$ \\
Bolivia & & \\
Simpatía hacia chilenos de... & Bolivianos \\
Argentinos & $.252^{* *}$ & Peruanos \\
Bolivianos & & $.124^{* *}$ \\
\hline
\end{tabular}

${ }^{*} p<.05 .{ }^{* *} p<.01 .{ }^{* * *} p<.001$

La mayoría de las correlaciones fueron bajas, pero destacan tres: las correlaciones entre la simpatía de la muestra hacia Perú y Bolivia (.603), la de los chilenos hacia ambos países (.667) y la que atribuyen los chilenos a los peruanos y bolivianos hacia ellos (.559).

\section{DisCusión}

En general, la imagen que tienen los sujetos de la muestra de su propia sociedad, la chilena, es más positiva y mejor que la que tienen de la peruana. Eso sucede, para poner un par de ejemplos, en materia de igualdad de oportunidades para todos los ciudadanos como también en la importancia del país en el contexto mundial, en la eficiencia del Estado y en el nivel cultural de la población. Chile es visto como un país que ofrece una mejor calidad de vida, en el cual la democracia es más sólida, con un mayor poderío militar, con una superior importancia en el contexto mundial y que está más cercano a integrarse al primer mundo que el Perú. En otros aspectos, sin embargo, es posible reconocer semejanzas en la percepción que tienen de ambas sociedades; así, en lo que se refiere a la presencia de pobreza en Chile y Perú, los promedios obtenidos son muy similares, algo que también ocurre en materia de agresividad militar y de nivel de corrupción.

Los resultados del presente estudio guardan concordancia con algunos de los datos ofrecidos en el Latinobarómetro (2013), en donde Chile se ubica por encima de Perú y Bolivia en cuanto a satisfacción con la vida, pero por debajo del resto de países encuestados. Asimismo, en lo que se refiere al nivel de progreso del país, Chile obtiene un puntaje mejor que Perú y Bolivia. En el Latinobarómetro (2013), 
la delincuencia es considerada el problema más importante por los peruanos, mucho más que entre bolivianos y chilenos. Lo mismo sucede con la corrupción.

También en la valoración de los rasgos de los peruanos y chilenos como individuos se reconoce una mejor imagen de estos últimos, si bien en materia de honestidad, responsabilidad y ahorro, los peruanos son percibidos como mejores que los chilenos. El peruano es visto como emprendedor, en tanto que el chileno es percibido como competitivo.

Es probable que este último aspecto tenga que ver con las conductas propias de los emigrantes que, instalados en su nuevo lugar de residencia, desarrollan conductas y actitudes de adaptación, de ganarse un nombre y un espacio en la sociedad que los acoge, y llevan un estilo de vida frugal que les permite ahorrar para cualquier eventualidad que pueda sucederles, así como para enviar dinero a sus familiares en el país de origen (Paine, 1974; Piore, 1979).

La simpatía de los chilenos hacia los argentinos es mayor que la que sienten hacia peruanos y bolivianos, siendo estos últimos los que despiertan el menor nivel de simpatía, algo que confirma los hallazgos de otros investigadores (Cárdenas, Gómez, Méndez y Yáñez, 2011; Sanhueza, Friz y Quintriqueo, 2014). A su vez, los integrantes de la muestra suelen ver a los argentinos como los que más simpatizan con ellos, mucho más que los peruanos y, en especial, que los bolivianos. Sobre la base de los resultados presentados en la tabla de correlaciones, puede afirmarse que, para la muestra, peruanos y bolivianos tienen una serie de características comunes que se expresan en el caso del presente trabajo en un nivel de simpatía relativamente semejante hacia los chilenos, y que hace que los chilenos, por su parte, experimenten un nivel de simpatía muy similar hacia bolivianos y peruanos.

Muchos autores peruanos han hablado de un sentimiento de inferioridad o de cierta insuficiencia de los peruanos frente a los chilenos, atribuyendo esto en buena medida a lo ocurrido durante la Guerra del Pacífico (Parodi Revoredo, 2014; Basadre, 2005; Klaiber, 1978). Esta confrontación tiene, sin duda alguna, un gran significado en la historia y en la imagen de los pueblos que la protagonizaron; para un distinguido historiador chileno, la guerra fue "el último acto fundacional de Chile como nación" (Fernandois, 2005, p. 37), mientras que para bolivianos y peruanos constituye un hecho doloroso y que ha ocasionado, en el caso de Bolivia, la pérdida de acceso al mar, algo que hoy esa nación reclama.

La Guerra del Pacífico y sus dolorosas consecuencias son hechos permanentemente recordados en Perú y Bolivia. Al menos en el Perú, no hay año en que no aparezca algún nuevo libro sobre este tema, y las dos más importantes conmemoraciones militares (la batalla del morro de Arica y el combate de Angamos) son cumplidas en medio de un solemne ceremonial, muchas veces transmitido por los medios de comunicación. Como lo señalan Tello Aguinaga y Guerrero Soto (2015), "la Guerra del Pacífico es uno de los acontecimientos más importantes de 
la historia republicana del Perú y que está más presente en la memoria colectiva peruana" (p. 9).

Los sentimientos negativos de peruanos y bolivianos con respecto a los chilenos son un elemento que no puede dejarse de lado a la hora de explicar los resultados de este estudio (Rodrigo Alsina, 2003), si bien por lo general suelen ser ignorados cuando se habla solo de aspectos cuantitativos en materia de inmigración. En la prensa, sin embargo, se suele hablar de resentimiento entre los peruanos por lo sucedido en la Guerra del Pacífico (véase, a modo de ejemplo, Cervantes-Bastidas, 2014).

De otro lado, a lo largo de su historia, los chilenos han ido configurando una imagen de su sociedad como poseedora de ancestros blancos, moderna y con una capacidad económica superior, exactamente en contraste con la imagen predominante entre ellos de los peruanos, como pobres, atrasados y con ancestros andinos, negros y asiáticos (Browne, Silva y Baessolo, 2010; Imilan, 2015). Ya en la Guerra del Pacífico, estas imágenes existían (McEvoy, 2011) y, tras el triunfo chileno sobre Perú y Bolivia, se reforzaron. Los resultados del presente estudio apuntan también en esa dirección.

\section{RefERENCIAS}

Ahumada, A., y Rivas Pardo, P. (2010). La cuestión marítima: Chile y Perú en La Haya [Documento de trabajo n. 37]. Buenos Aires: Centro Argentino de Estudios Internacionales.
Altamirano, T. (1992). Éxodo: peruanos en el exterior. Lima: Pontificia Universidad Católica del Perú.

Altamirano, T. (1996). Migración, el fenómeno del siglo. Peruanos en Europa, Japón y Australia. Lima: Pontificia Universidad Católica del Perú.

Aranda Bustamante, G. G. (2010). Mesías andinos. Continuidad y discontinuidad entre Velasco Alvarado, Fujimori y Ollanta Humala. Santiago de Chile: Editorial Universitaria.

Araujo, K., Legua, M. C., y Ossandón, L. (2002). Migrantes andinas en Chile. El caso de la migración peruana. Santiago de Chile: Fundación Instituto de la Mujer.

Arias, S. G., Moreno, M. R., y Núñez, G. D. (2010). Inmigración latinoamericana en Chile: analizando perfiles y patrones de localización de la comunidad peruana en el área metropolitana de Santiago (AMS). Tiempo y Espacio, 25. Recuperado de http://www.ubiobio.cl/miweb/ webfile/media/222/Espacio/2010/ INMIGR ACI\%C $\% \% 93 \mathrm{~N} \% 20 \mathrm{LA}$ TINOAMERICANA $\% 20$ EN $\% 20$ CHILE.pdf

Artaza Rouxel, M., y Milet García, P. (Eds.). (2007). Nuestros vecinos. Santiago de Chile: RIL Editores.

Bahamonde, P. (2013). Actitudes de los chilenos hacia las orientaciones aculturativas de los inmigrantes peruanos y su relación con variables interculturales. Praxis. Revista de Psicología, 15(24), 29-55. 
Basadre, J. (2005). Historia de la República del Perú. Lima: El Comercio.

Brockmann, R. (2014). Bolivia, Chile (Perú) y el mar: entre la obsesión y la indiferencia. En S. Molina (Ed.), Cuadrar el círculo: las propuestas de solución al conflicto entre Chile y Bolivia (pp. 7993). Santiago de Chile: LOM.

Browne, R., Silva, V., y Baessolo, R. (2010). Intercultural Journalism: Peruvian and Bolivian Representation in the Chilean Daily Press News. Comunicar. Scientific Journal of Media Literacy, 18(35), 85-93.

Cárdenas, M., Gómez, F., Méndez, L., y Yáñez, S. (2011). Reporte de los niveles de prejuicio sutil y manifiesto hacia los inmigrantes bolivianos y análisis de la relación con variables psicosociales. Psicoperspectivas. Individuo y Sociedad. 10(1), 125-143.

Cavieres Figueroa, E. (2006). Chile-Perú, la historia y la escuela. Conflictos nacionales, percepciones sociales. Valparaíso: Pontificia Universidad Católica de Valparaíso.

Cervantes-Bastidas, A. A. (24 de enero del 2014). Chile y Perú en La Haya: el cholito resentido vs. el matón del barrio (I) [Mensaje en un blog]. Recuperado de http://www.huffingtonpost.com/arman do-a-cervantesbastidas/chile-peru-enla-haya-el-_b_4642227.html

Corporación Latinobarómetro. (2013). Informe 2013. Recuperado de http:// www.latinobarometro.org/documentos/ LATBD_INFORME_LB_2013.pdf
Correa, J. (2011). Ser "inmigrante" en Chile. La experiencia del racismo cotidiano de peruanos y peruanas en la ciudad de Santiago (tesis para optar el título de socióloga). Universidad de Chile, Santiago de Chile.

Cluny, C. M. (2008). Atacama. Ensayo sobre la guerra del Pacífico, 18791883. México D. F.: Fondo de Cultura Económica.

Doña-Reveco, C., y Levinson, A. (2012). Chile: A Growing Destination Country in Search a Coherent Approach to Migration. Country Profiles. Migration Policy Institute, Washington, D. C. Recuperado de http://www.migration policy.org/article/chile-growingdestination-country-search-coherentapproach-migration

Éxito peruano, lecciones para Chile [Editorial]. (14 de febrero del 2013). El Mercurio. Recuperado de http: //www.elmercurio.com/blogs/2013/02/ 14/9258/Exito-peruano-leccionespara-Chile.aspx

Fernandois, J. (2005). Mundo y fin de mundo. Chile en la política mundial 1900-2004. Santiago de Chile: Pontificia Universidad Católica de Chile.

González Madariaga, E. (1970). Nuestras relaciones con Argentina. Una historia deprimente. Del Tratado de Paz, Amistad, Comercio y Navegación de 1856 al Tratado de Límites de 1881. Santiago de Chile: Andrés Bello.

González, R., Sirlopú, D., y Kessler, S. (2010). Prejudice among Peruvians 
and Chileans as a Function of Identity, Intergroup Contact, Acculturation Preferences, and Intergroup Emotions. Journal of Social Issues, 66(4), 803-824.

González Riesle, A. (2013). Perú-Chile: imágenes mutuas. Liberabit, 20(1), 13-28.

Hernández Sánchez, M. S. (2011). La migración peruana en Chile y su influencia en la relación bilateral durante el gobierno de Michelle Bachelet (tesis para optar el grado de magíster en Estudios Internacionales). Universidad de Chile, Instituto de Estudios Internacionales, Santiago de Chile.

Hosiasson, L. J. (2011). Nação e imaginação na Guerra do Pacífico. São Paulo: Editora da Universidade do São Paulo.

Imilan, W. A. (2015). Performing National Identity through Peruvian Food Migration in Santiago de Chile. Fennia, 193(2), 227-241.

Klaiber, J. (1978). Los "cholos" y los "rotos": actitudes raciales durante la guerra del Pacífico. Histórica, 2(1), 27-37.

Lacoste, P., y Jiménez Cabrera, D. (2016). El enclaustramiento de Bolivia y el factor Argentina. Sí Somos Americanos. Revista de Estudios Transfronterizos, 16(1), 119-145.

Lahoz i Ubacha, S., y Forns i Santacana, M. (2016). Discriminación percibida, afrontamiento y salud mental en migrantes peruanos en Santiago de Chile. Psicoperspectivas. Individuo y Sociedad, 15(1), 157-168.
Leiva Lavalle, P. (Ed.). (2010). Diálogos sobre La Haya. El límite marítimo entre Chile y Perú. Santiago de Chile: Fundación Konrad Adenauer; Universidad Miguel de Cervantes.

León, R. (2004). ¿Qué piensan y qué sienten los jóvenes limeños acerca de la guerra del Pacífico? Un estudio. Teoría e Investigación en Psicología, 13, 133-164.

León, R. (2006). Perú, Chile y la guerra del Pacífico: ¿qué piensan, qué creen, qué sienten los universitarios en los dos países? Lima: Universidad Ricardo Palma.

McEvoy, C. (2011). Guerreros civilizadores. Política, sociedad y cultura en Chile durante la guerra del Pacífico. Santiago de Chile: Universidad Diego Portales.

Milet, P. V. (2004). Chile-Perú: las dos caras de un espejo. Revista de Ciencia Política, 24(2), 228-235.

Ministerio de Relaciones Exteriores del Perú. (s. f.). El contencioso sobre delimitación marítima entre el Perú y Chile ante la Corte Internacional de Justicia. Recuperado de http://www. rree.gob.pe/noticias/Documents/triptico_informativo_peru_la_haya.pdf

Ministerio de Relaciones Exteriores de Chile. (2013). Evaluación de las relaciones comerciales entre Chile y Perú a cuatro años de la entrada en vigencia del acuerdo de libre comercio. Santiago de Chile: Autor.

Mora, C. (2008). The Peruvian Community in Chile. Peace Review: A Journal of Social Justice, 20(3), 339-347. 
Muñoz, S. (2005). Peruvian Migration to Chile: Challenges for National Identity, Human Rights and Social Policy [Informe CLASPO]. Recuperado de http://lanic.utexas.edu/project/etext/ 1lilas/claspo/fieldreports/munoz05.pdf

Navarrete Yáñez, B. (2007). La "quinta oleada migratoria" de peruanos a Chile: los residentes legales. Revista Enfoques, 7, 173-195.

Núñez, L., y Stefoni, C. (2004). Migrantes andinos en Chile. ¿Transnacionales o sobrevivientes? Enfoques, 3, 103-123.

Paerregaard, K. (2008). Peruvian Dispersed. A Global Ethnography of Migration. Maryland: Lexington Books.

Paine, S. (1974). Exporting Workers: The Turkish Case. Cambridge: Cambridge University Press.

Parodi Revoredo, D. (2014). Conflicto y reconciliación. El litigio contra Chile en la Corte de La Haya. Lima: Universidad Peruana de Ciencias Aplicadas.

Piore, M. J. (1979). Birds of Passage. Cambridge: Cambridge University Press.

Riquelme, J., y Alarcón, G. (2008). El peso de la historia en la inmigración peruana en Chile. Polis, 7(20), 299-310.

Rodrigo Alsina, M. (2003). Inmigración y comunicación. En F. Contreras, R. González, y F. Sierra (Eds.), Comunicación, cultura y migración. Sevilla: Dirección General de Coordinación de Políticas Migratorias. Junta de Andalucía.
Sanhueza, S. V., Friz, M.C., y Quintriqueo, S. (2014). Estudio exploratorio sobre las actitudes y comportamiento del profesorado de Chile en contextos de escolarización de alumnado inmigrante. Revista Electrónica de Investigación Educativa, 16(3), 148-162.

Sater, W. F. (2007). Andean Tragedy: Fighting the War of the Pacific, 18791884. Lincoln, NE: University of Nebraska Press.

Sirlopú, D., y León, R. (2016). Actitudes hacia la paz y la guerra. Identidad social e ideología en universitarios peruanos. En I. Magaña, A. Dorna e I. Torres (Eds.), Contribuciones a la psicología política en América Latina. Contextos y escenarios actuales (pp. 199-219). Santiago de Chile: Centro de Estudios Enzo Faletto; RIL Editores.

Stefoni, C. (2001). Representaciones culturales y estereotipos de la migración peruana en Chile. Buenos Aires: Consejo Latinoamericano de Ciencias Sociales.

Stefoni, C. (2002). Mujeres inmigrantes peruanas en Chile. Papeles de Población, 8(33), 117-144.

Stefoni, C. (2003). Inmigración peruana en Chile. Una oportunidad a la integración. Santiago de Chile: Editorial Universitaria.

Tello Aguinaga, K., y Guerrero Soto, N. (2015). Premio 2015: Integración y Buena Vecindad Chile-Perú/PerúChile. Lima: Pontificia Universidad Católica del Perú; Konrad Adenauer Stiftung, Universidad de Chile. 
Tory, S. (14 de junio del 2013). The two faces of Chile's immigration boom. The Santiago Times. Recuperado de http://santiagotimes.cl/the-two-facesof-chiles-immigration

Torres, A., e Hidalgo, R. (2009). Los peruanos en Santiago de Chile: transformaciones urbanas y percepción de los inmigrantes. Polis, 8(22), 307-326.
Universidad de Talca. (2005). Situación de los peruanos en Chile. Talca: Centro de Estudios de Opinión Ciudadana.

Vásquez, T. (2014). La migración peruana a Chile: el crecimiento de la comunidad binacional peruano-chilena. Revista Argumentos, 8(1), 30-37. 